\title{
Mechanisms of the laser plume expansion during the ablation of $\mathrm{LiMn}_{2} \mathrm{O}_{4}$
}

\author{
S. Canulescu, ${ }^{1, a)}$ E. L. Papadopoulou, ${ }^{2, b)}$ D. Anglos, ${ }^{2, c)}$ Th. Lippert,, ${ }^{3, d)}$ C. W. Schneider, ${ }^{3, e)}$ \\ and A. Wokaun 3, f) \\ ${ }^{1}$ EMPA-Materials Science \& Technology, Feuerwerkerstrasse 39, CH-3602 Thun, Switzerland \\ ${ }^{2}$ Institute of Electronic Structure and Laser, Foundation for Research and Technology-Hellas, \\ P.O. Box 1385, 71110 Heraklion, Crete, Greece \\ ${ }^{3}$ Department of General Energy Research, Paul Scherrer Institut, 5232 Villigen PSI, Switzerland
}

(Received 25 May 2008; accepted 6 February 2009; published online 24 March 2009)

\begin{abstract}
Films of $\mathrm{LiMn}_{2} \mathrm{O}_{4}$ prepared by pulsed laser ablation deposition are typically lithium deficient when grown at background pressures ranging between $10^{-4}$ and $20 \mathrm{~Pa}$. The deficiency of light atomic species such as lithium in $\mathrm{LiMn}_{2} \mathrm{O}_{4}$ thin films occurs as a result of the different behavior of the species during plume expansion and the deposition of the film at elevated deposition temperatures. The plasma plume evolution in vacuum and $20 \mathrm{~Pa}$ oxygen pressure are studied using two spectroscopic techniques: emission spectroscopy and plume imaging. Higher velocities and a wider spatial distribution of lithium atoms are observed in vacuum when compared with manganese and oxygen species. Plume species are slowed down due to collisions with gas molecules when ablating $\mathrm{LiMn}_{2} \mathrm{O}_{4}$ in an oxygen atmosphere. As a result, a strong deceleration of the plasma front occurs, and the effect is more pronounced for the light species, e.g., Li. Comparing the spatial manganese and lithium distribution within the plasma, the lithium species are again scattered into a wider angular range. These similar spatial distributions of $\mathrm{Li}$ atoms detected in the pressure range between $10^{-4}$ and $20 \mathrm{~Pa}$ suggest that it is not possible to achieve a congruent lithium transfer to a growing film if the target contains heavier elements besides lithium. The general implications for the ablation of materials containing a combination of light and heavy elements are that as-grown films are inherently deficient with respect to the content of the light elements. If the mass ratio between the light and the heavy elements is not too different, is should be possible to find a set of deposition parameters which will result in the growth of a film with the desired composition. () 2009 American Institute of Physics. [DOI: 10.1063/1.3095687]
\end{abstract}

\section{INTRODUCTION}

Lithium manganese oxides are considered to be attractive cathode materials for Li-ion batteries. Their main advantages are low cost, nontoxicity, and availability when compared to $\mathrm{LiCoO}_{2}$ and $\mathrm{LiNiO}_{2}$. 1 Recent studies have also shown that $\mathrm{LiMn}_{2} \mathrm{O}_{4}$ and $\mathrm{LiMnO}_{2}$ can be employed for rechargeable lithium batteries. ${ }^{2}$ Due to their high energy density, Li batteries can be used as a rechargeable power source in mobile phones, digital cameras, and other small electronic devices.

It has been suggested that high quality $\mathrm{LiMn}_{2} \mathrm{O}_{4}$ thin films can be obtained by pulsed laser deposition (PLD), ${ }^{3-5}$ although the Li content of these films is in question. PLD is a simple deposition method to obtain thin films with a high degree of congruent stoichiometric transfer of material from

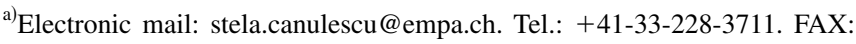
+41-33-228-4490.

${ }^{b)}$ Electronic mail: eviep@iesl.forth.gr. Tel.: +30-2810391132. FAX: +302810391305.

c)Electronic mail: anglos@iesl.forth.gr. Tel.: +30-2810391154. FAX: +302810391305.

d) Author to whom correspondence should be addressed. Electronic mail: thomas.lippert@psi.ch. Tel.: + 41-(0)56-310-4076. FAX: 0041-(0)56-3102688.

e) Electronic mail: christof.schneider@psi.ch. Tel.: + 41-(0)56-310-4122. FAX: 0041-(0)56-310-2688.

${ }^{\mathrm{f})}$ Electronic mail: alexander.wokaun@psi.ch. Tel.: + 41-(0)56-310-2751. FAX: 0041-(0)56-310-4416.
}

a target to a substrate. Nevertheless, some drawbacks in PLD of oxides include deficiencies in the oxygen content of the as-grown film or losses in the light species. In the case of $\mathrm{LiNbO}_{3}$, a Li deficiency for thin films was reported. ${ }^{6}$ Perea $e t$ $a l^{7}$ demonstrated that the plume induced by ablating $\mathrm{LiNbO}_{3}$ consists of a wider distribution of $\mathrm{Li}$ atoms when compared to $\mathrm{Nb}$. They also observed a delayed release of $\mathrm{Li}$ in the plume, which could explain the low Li content observed in the film composition. ${ }^{7}$ However, whether these observations are also relevant and applicable for the deposition of $\mathrm{LiMn}_{2} \mathrm{O}_{4}$ has not been analyzed yet.

Previous studies on PLD-grown $\mathrm{LiMn}_{2} \mathrm{O}_{4}$ films revealed a Li deficiency when compared with the target material composition. ${ }^{4}$ Films grown under vacuum conditions are highly deficient in $\mathrm{Li}$ and $\mathrm{O}$, while the best transfer is obtained at an oxygen pressure of $20 \mathrm{~Pa}$. In addition, a preferential resputtering of $\mathrm{Li}$ from the growing films at low background pressures is noted as a result of the high kinetic energy of the ablated species. ${ }^{8}$ Even under the best conditions, a lithium deficiency of more than $5 \%$ remained and we concluded that an additional source for the observed Li deficiency must exist. To investigate the origin of the observed Li deficiency, we studied in detail the PLD process of $\mathrm{LiMn}_{2} \mathrm{O}_{4}$ for two distinct different pressure regimes, thereby concentrating on the formation and expansion dynamics of the plasma.

The laser induced ablation process consists of three main 
steps: (i) interaction of the laser beam with the bulk target; (ii) plasma formation, heating, and initial three-dimensional isothermal expansion; and (iii) adiabatic expansion and deposition of thin films. In nanosecond laser ablation the first two processes occur during the laser pulse, while the last process initiates after the laser pulse. To study the plume dynamics during the PLD process several spectroscopic techniques such as ion probe, ${ }^{9}$ mass spectrometry, ${ }^{10}$ emission spectroscopy, ${ }^{11}$ and plume imaging ${ }^{12}$ have been employed.

The free expansion of the plume in vacuum can be described as adiabatic. With increasing background pressure, the plume behavior changes dramatically depending on the pressure and type of gas used. ${ }^{9}$ As a result of the increase in collisions a shock plume front between the background gas molecules and plume species is formed, inducing a plume confinement and hence a reduction in the velocity of the plume species. $^{13}$

A simplified model of plume expansion in an oxygen atmosphere has been proposed by Arnold et al. ${ }^{14}$ in which the plume is considered to be a hemispherical cloud described by spatial and temporal coordinates $\rho$ and $t$, respectively. The initial stage of a plume is similar to an inertial expansion into vacuum with $\rho \propto t$, while the later expansion can be described by a point-blast model with $\rho \propto t^{2 / 5} .{ }^{15}$ Another model by Lunney and co-workers ${ }^{16,17}$ is based on the adiabatic expansion model of Anisimov et al. ${ }^{18}$ and Singh and Naryan. ${ }^{19}$ The model by Lunney and co-workers ${ }^{16,17}$ has been developed for the successful analysis of time-of-flight ion-probe measurements to obtain the plasma and electron temperature.

We study the dynamics of the plume induced by laser ablation of $\mathrm{LiMn}_{2} \mathrm{O}_{4}$ both in vacuum and in oxygen background gas at a pressure, which has been shown to yield the lowest Li deficiency. ${ }^{8}$ The temporal and spatial plume evolution is investigated using time resolved emission spectroscopy and plume imaging. The combination of these two methods in particular will help to elucidate mechanisms that explain the origin of the $\mathrm{Li}$ deficiency in the deposited $\mathrm{LiMn}_{2} \mathrm{O}_{4}$ films.

\section{EXPERIMENTAL}

The measurements were performed in a high vacuum chamber at a base pressure of the order of $10^{-4} \mathrm{~Pa}$. A 248 $\mathrm{nm} \mathrm{KrF}$ excimer laser (Lambda-Physik LPX200, $\tau_{\mathrm{FWHM}}$ $=34 \mathrm{~ns}$ ) was focused on a rotating $\mathrm{LiMn}_{2} \mathrm{O}_{4}$ target at an incident angle of $45^{\circ}$ to minimize crater formation. The laser fluence was $2 \mathrm{~J} \mathrm{~cm}^{-2}$ and the spot size on the target was $1 \mathrm{~mm}^{2}$.

Space and time resolved emission spectroscopy measurements were performed in vacuum and in partial oxygen pressure of $20 \mathrm{~Pa}$. The spectra were collected by focusing the emission onto a quartz fiber (at 1:1 magnification configuration) through an appropriate observation port on the chamber. The exit of the fiber was attached to the entrance slit of a spectrograph (TRIAX-320, Jobin Yvon-Spex) equipped with three holographic gratings with 600, 1800, and 2400 lines $/ \mathrm{mm}$, providing a spectral resolution of $0.4,0.15$, and $0.1 \mathrm{~nm}$, respectively. The emission was recorded with an
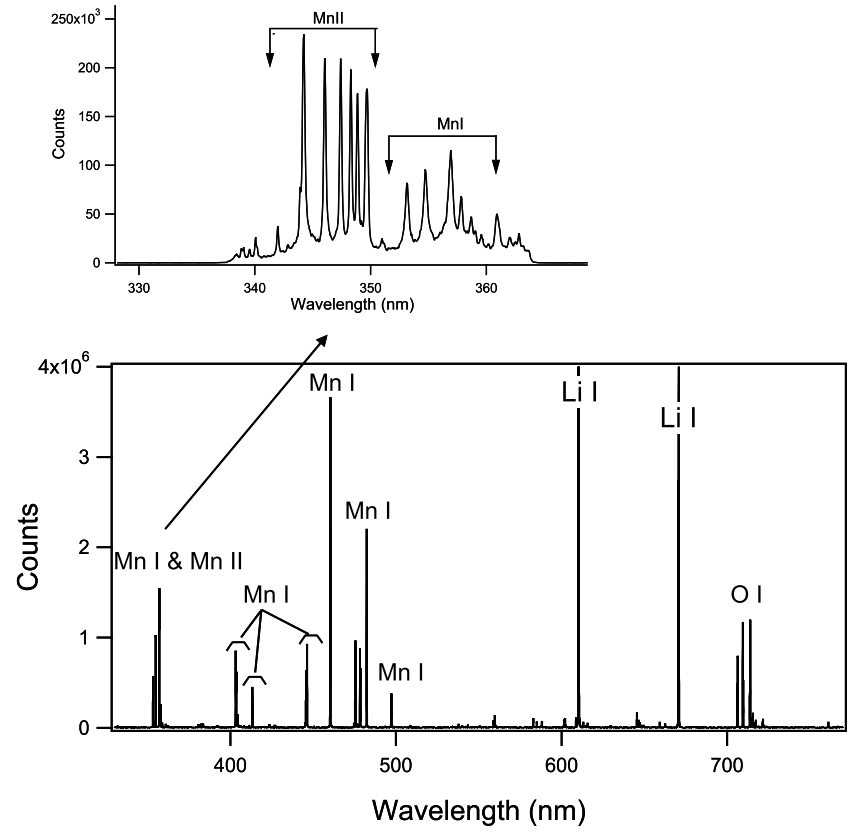

FIG. 1. Optical emission spectra generated from the vacuum laser ablation of a $\mathrm{LiMn}_{2} \mathrm{O}_{4}$ target using a $\mathrm{KrF}$ excimer laser (fluence $2 \mathrm{~J} \mathrm{~cm}^{-2}$ ) as an irradiation source.

intensified charge coupled device (ICCD, DH520-18F, Andor technology) gated for an interval of $40 \mathrm{~ns}$. Emission spectra were investigated in the range of 300-900 $\mathrm{nm}$. The emission spectra were collected at different distances from the target by translating the fiber along the direction of the plume expansion with a spatial resolution of $0.5 \mathrm{~mm}$. The temporal evolution of the plume was also studied for delay times of 120-2120 ns. The minimum delay time of $120 \mathrm{~ns}$ with respect to the laser pulse is due to the electronics used.

Time resolved images of the plume were monitored by decoupling the camera, working in time-gated detection mode, from the spectrograph and focusing the optical emission onto the $1024 \times 256$ diode array with a $1: 1$ magnification. Either the total emission was recorded or just a fraction of the emission transmitted through a band-pass interference filter for selected species. No corrections have been applied to the spectra to account for the varying detector sensitivity across the wavelength range studied.

\section{RESULTS}

\section{A. Emission spectroscopy}

An emission spectrum corresponding to the ablation of $\mathrm{LiMn}_{2} \mathrm{O}_{4}$ from 300 to $900 \mathrm{~nm}$ is shown in Fig. 1. The most intense lines are Li I (610 and $670 \mathrm{~nm})$, followed by Mn I, Mn II, and O I. Other intense peaks observed at wavelengths above $700 \mathrm{~nm}$ are second order diffraction peaks. No emission arising from diatomic species such as $\mathrm{MnO}(558.5 \mathrm{~nm})$ (Ref. 20) was observed.

The emission lines of the Mn I and Mn II species (340$350 \mathrm{~nm}$ ) were investigated in detail (see Table I). Here, the emission of the plume in vacuum is compared to the emission at $20 \mathrm{~Pa}$ oxygen pressure. The temporal evolutions of the emission corresponding to the Li I, Mn I, and Mn II species in vacuum and in $20 \mathrm{~Pa}$ oxygen are shown in Figs. 
TABLE I. Velocities of the plume species obtained from emission spectroscopy.

\begin{tabular}{|c|c|c|c|c|}
\hline Species & $\begin{array}{c}\text { Emission } \\
\text { wavelength } \\
(\mathrm{nm})\end{array}$ & $\begin{array}{l}\text { Excited } \\
\text { state lifetimes } \\
(\mathrm{ns})\end{array}$ & $\begin{array}{c}\text { Velocities } \\
\text { in vacuum } \\
(\mathrm{m} / \mathrm{s})\end{array}$ & $\begin{array}{c}\text { Velocities } \\
\text { at } 20 \mathrm{~Pa} \mathrm{O}_{2} \text { (almost } \\
\text { collision-free } \\
\text { expansion) } \\
(\mathrm{m} / \mathrm{s})\end{array}$ \\
\hline Li I & 670 & 27 & $1.8( \pm 0.01) \times 10^{4}$ & $1.6( \pm 0.01) \times 10^{4}$ \\
\hline Mn I & 355 & 5 & $1.2( \pm 0.01) \times 10^{4}$ & $7.8( \pm 0.01) \times 10^{3}$ \\
\hline Mn II & 340 & 10 & $1.6( \pm 0.02) \times 10^{4}$ & $1.0( \pm 0.02) \times 10^{4}$ \\
\hline
\end{tabular}

2(a) and 2(b), respectively. The data indicate that the emission intensity profiles in the oxygen background gas are sharper as compared to the emission profiles in vacuum. This can be attributed to the confinement of the plume, which is induced by the collisions of the species in the plume with the background gas.

To understand the plume expansion mechanism, we have recorded the time $t$ at which the maximum emission intensity is attained as a function of the distance from the target $d$. This time-distance $(t-d)$ evolution for $\mathrm{Li} \mathrm{I}$ and $\mathrm{Mn}$ II is shown in Figs. 3(a) and 3(b), respectively. In vacuum, the emission intensity of the Mn II species [see Fig. 3(b)] disappears at around $5 \mathrm{~mm}$, while in the case of $\mathrm{Li}$ I the emission intensity vanishes at around $10 \mathrm{~mm}$ from the target [see Fig. 3(a)]. Similar numbers for a decay of the emission intensity
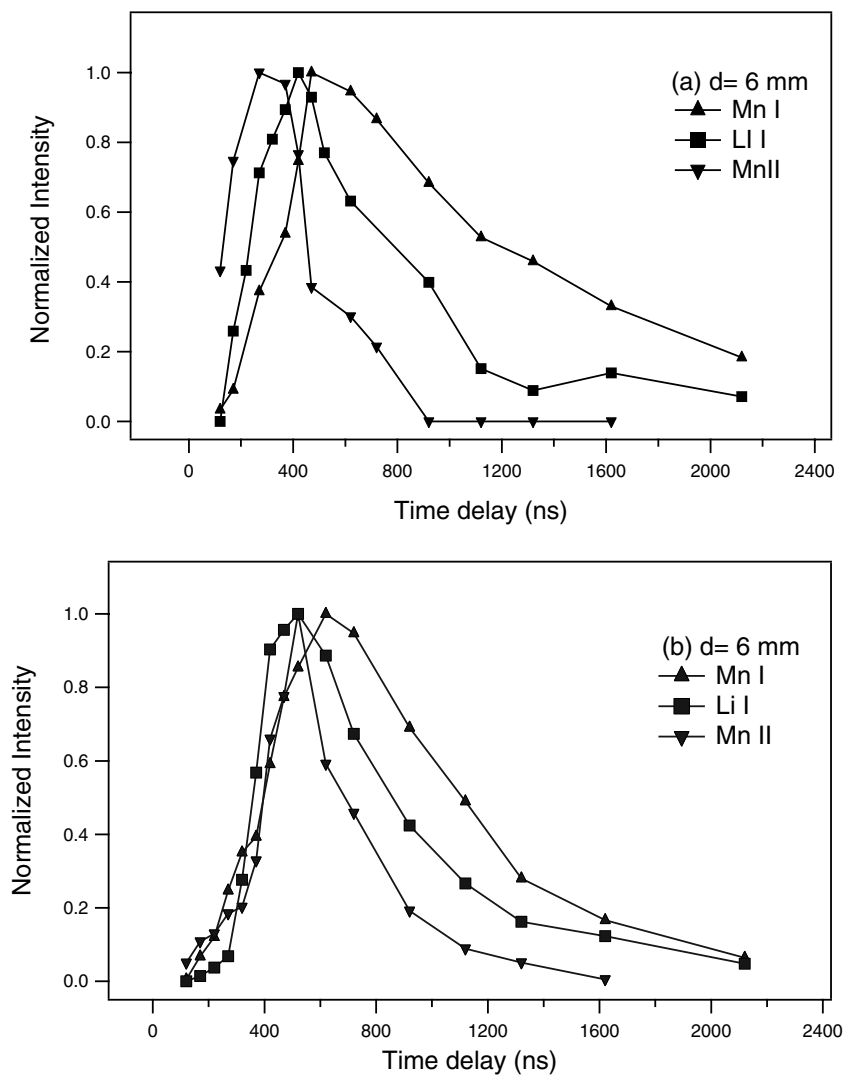

FIG. 2. Time dependence of the normalized emission intensity from Mn I, $\mathrm{Mn}$ II, and $\mathrm{Li}$ I species recorded at $6 \mathrm{~cm}$ from the target surface in (a) vacuum and (b) at $20 \mathrm{~Pa}$ oxygen using a laser fluence of $2 \mathrm{~J} \mathrm{~cm}^{-2}$. Note that the delay time starts at $120 \mathrm{~ns}$, which is the delay imposed by the electronics response.
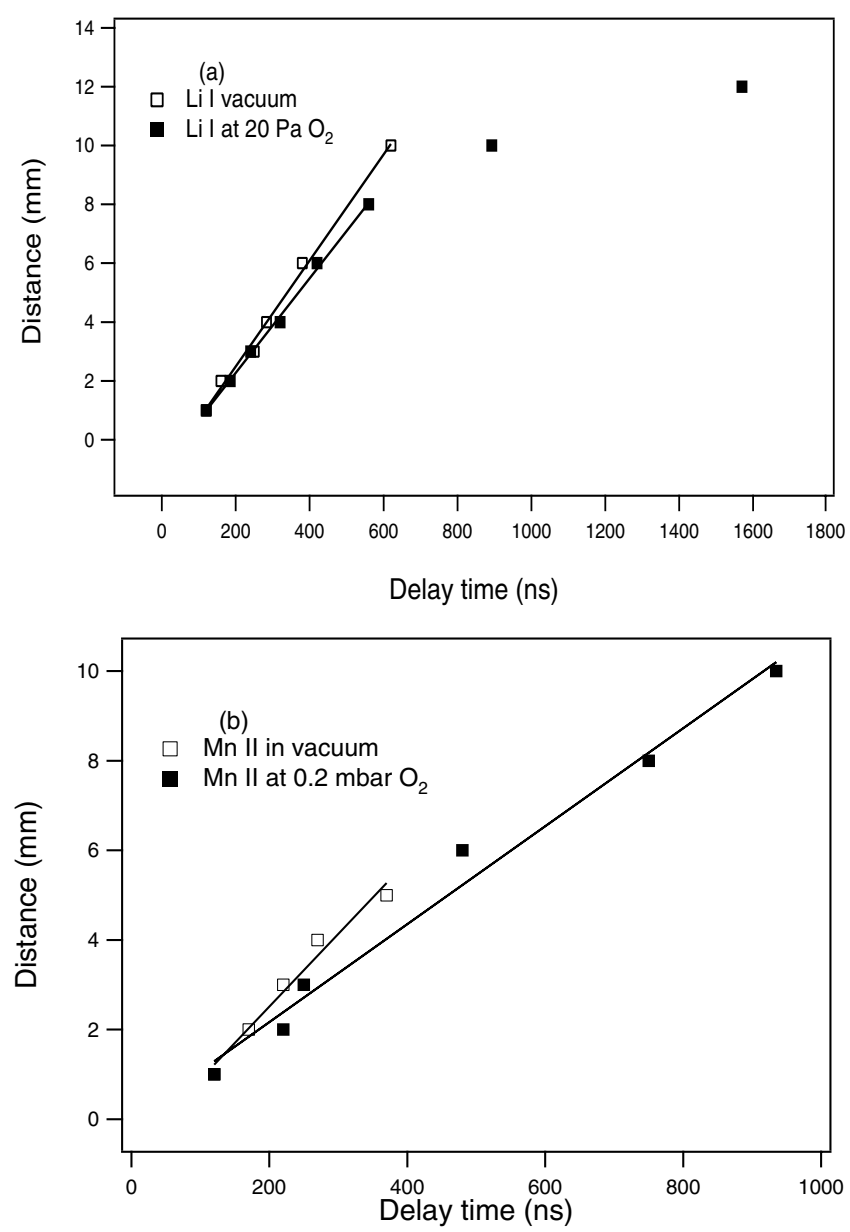

FIG. 3. [(a) and (b)] Distance vs time dependence of the Li I and Mn II species in vacuum and at $20 \mathrm{~Pa}$ oxygen pressure, respectively. The straight line shows the linear fit in vacuum and in the free region of the plume.

of around $5 \mathrm{~mm}$ away from the target were observed for $\mathrm{Mn}$ I and O I (not shown here). As the lifetimes of the excited state plume species are of the order of several $10 \mathrm{~ns}$ (see Table I), the decay time for the emission intensity is expected to be comparable. A prolonged emission of the plume species, however, indicates that additional mechanisms such as electron recombination are involved to create new excite states during the ablation and expansion of the plume in vacuum.

At $20 \mathrm{~Pa}$, the emission intensity observed extends over longer times and larger distances (Fig. 3). This can be attributed to additional collision induced excitation processes with the oxygen background molecules. At delay times $<600 \mathrm{~ns}$, the background gas has a little effect on the plume expansion and the $t$ - $d$ correlations for the vacuum and background gas are similar, suggesting an almost collision-free expansion. The vacuum velocities extracted from the linear fits are $1.8( \pm 0.02) \times 10^{4}$ and $1.6( \pm 0.02) \times 10^{4} \mathrm{~m} / \mathrm{s}$ for $\mathrm{Li} \mathrm{I}$ and $\mathrm{Mn}$ II, respectively, while $\mathrm{Mn}$ I was found to expand with $1.2( \pm 0.01) \times 10^{4} \mathrm{~m} / \mathrm{s}$ (see Table I). The corresponding velocities at $20 \mathrm{~Pa}$ oxygen background pressure are reduced compared to the vacuum velocities and also listed in Table I. At larger delay times and distances, the $d$ - $t$ plot deviates from a linear correlation. An attenuation of the emission intensity is observed due to the presence of the background 

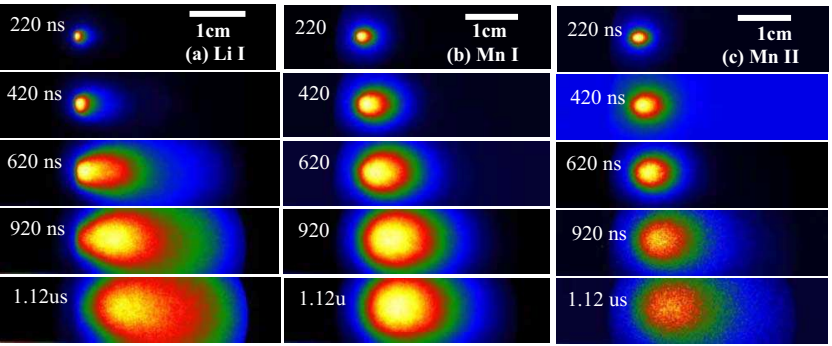

FIG. 4. (Color online) ICCD images of the emission of the plume induced by ablation of the $\mathrm{LiMn}_{2} \mathrm{O}_{4}$ target in vacuum. All images were collected at various gains in order to improve the signal to noise ratio. The images were filtered using appropriate band width filters allowing detection of single species such as (a) Li I, (b) Mn I, and (c) Mn II. Each image is normalized with respect to the maximum intensity. The laser fluence was set at $2 \mathrm{~J} \mathrm{~cm}^{-2}$ and the target position is indicated by the dashed lines.

gas, in particular at delay times larger than $1 \mu$ s. To study the plume dynamics on all relevant time scales, we therefore performed plume imaging analysis of spatial dimension of up to $3 \mathrm{~cm}$.

\section{B. Plume imaging in vacuum}

Time resolved plume imaging gives additional information about the internal dynamics of the plume and allows emission detection over large areas. ${ }^{21}$ This is illustrated in Fig. 4 were ICCD images of the ablation plume of $\mathrm{LiMn}_{2} \mathrm{O}_{4}$ in vacuum for different species at different times are presented. The gain for each image was appropriately adjusted to compensate for the emission intensity reduction at greater distances or times during the measurements. Each image was normalized with respect to its maximum intensity. The total optical emission was filtered to allow the detection of single species from the plume. The band filters used, together with the emission lines investigated, are specified in Table II.

The filtered emission images for (a) Li I, (b) Mn I, and (c) Mn II are shown in Fig. 4 with the delay time indicated in each picture. At $t \leq 420 \mathrm{~ns}$, a hemispherical expansion of the plume is observed for all species. At longer times, the plume species show different dynamics. The emission profiles cor-

TABLE II. Wavelength and relative intensities of emission lines of manganese and lithium species detected in plume imaging experiments and dielectric filters used.

\begin{tabular}{clll}
\hline \hline $\begin{array}{c}\text { Wavelength } \\
(\mathrm{nm})\end{array}$ & Configuration & $\begin{array}{l}\text { Relative } \\
\text { intensity }\end{array}$ & Filters \\
\hline
\end{tabular}

Lithium neutrals (Li I)

670.68

$$
1 s^{2} 2 p \rightarrow 1 s^{2} 2 s
$$

3600

FWHM of $10.21 \mathrm{~nm}$ centered at $670.7 \mathrm{~nm}$

354.78

353.21

359.5

344.19

346.03

347.40
Manganese neutrals (Mn I) $3 d^{6}\left({ }^{3} H\right) 4 p \rightarrow 3 d^{6}\left({ }^{3} G\right) 4 s$ $3 d^{6}\left({ }^{3} G\right) 4 s \rightarrow 3 d^{6}\left({ }^{3} H\right) 4 p$ $3 d^{6}\left({ }^{5} D\right) 4 s \rightarrow 3 d^{6}\left({ }^{5} D\right) 4 p$

1300

1100

Manganese ions (Mn II)

$$
3 d^{5}\left({ }^{6} S\right) 4 p \rightarrow 3 d^{6}
$$

$3 d^{5}\left({ }^{6} S\right) 4 p \rightarrow 3 d^{6}$

$3 d^{5}\left({ }^{6} S\right) 4 p \rightarrow 3 d^{6}$
290

FWHM of $10.04 \mathrm{~nm}$ centered at $354 \mathrm{~nm}$
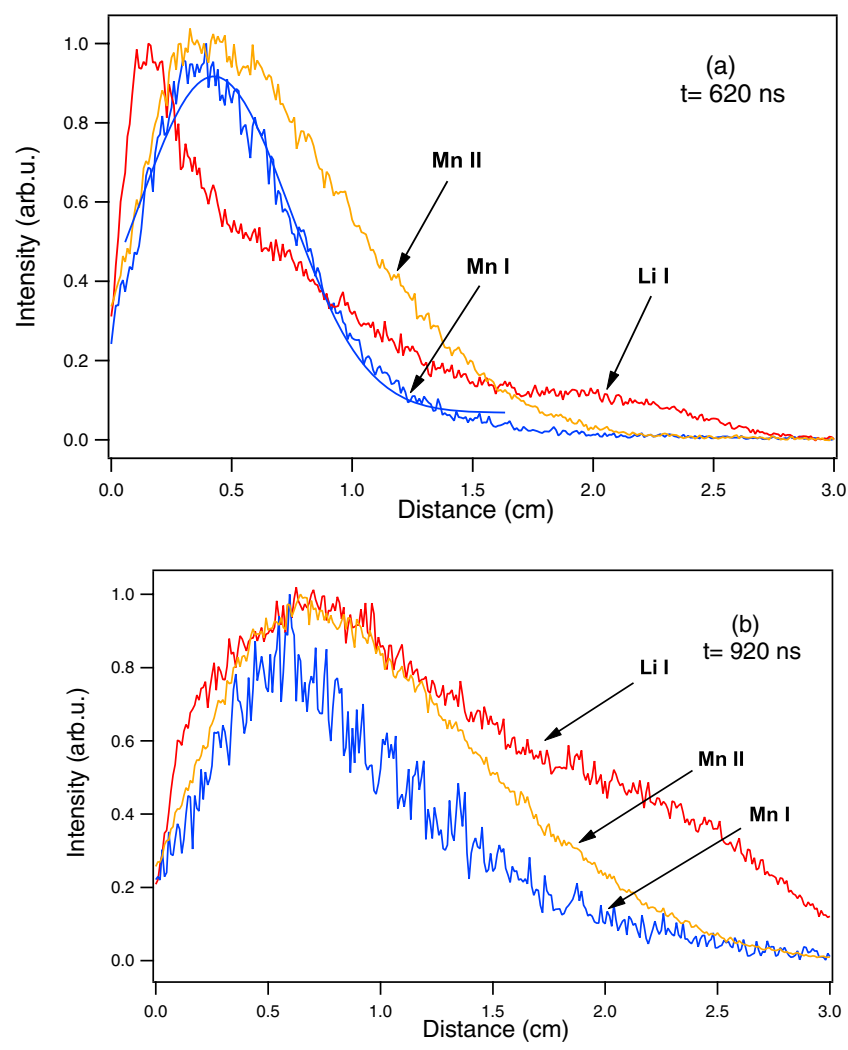

FIG. 5. (Color online) Emission intensity profiles obtained from plume imaging of Li I, Mn I, and Mn II species at a delay time of (a) 620 and (b) 920 ns. A Gaussian fit of the Mn II signal is also included. The normalized intensities are shown and the measurements were performed in vacuum at a laser fluence of $2 \mathrm{~J} \mathrm{~cm}^{-2}$.

responding to Mn I and Mn II maintain an almost hemispherical shape of up to $1200 \mathrm{~ns}$. The weak intensity of Mn II species is due to the low relative emission intensity as compared to Mn I (see Table II), a lower amount of Mn II present in the plume or a combination of both. The amount of ionized Mn species can also be partially reduced due to a recombination with electrons to form neutral Mn I species.

The emission arising from the Li species is hemispherical for the first $600 \mathrm{~ns}$, followed by an elongation along the expansion direction. This elongated expansion is attributed to the high velocities of the species expanding into vacuum. ${ }^{22,23}$ Furthermore, after $900 \mathrm{~ns}$ the trailing plume edge is still in close contact with the target surface, resulting in the formation of a flat "interface" between target surface and plume (see Fig. 4). The plume images also indicate an increased angular broadening of the plume for $\mathrm{Li} \mathrm{I}$ as compared to $\mathrm{Mn}$ I and Mn II, but a quantification of the angular distribution for $\mathrm{Li} \mathrm{I}$ is difficult due to the limited field of view of the detector system.

The plume imaging data were analyzed to determine the temporal and spatial evolution of the plume. Plume emission profiles along the expansion direction were extracted for Li I, Mn I, and Mn II. The evolution of the plume emission along the normal to the target surface recorded at two different delay times (620 and $920 \mathrm{ns)}$ is shown in Figs. 5(a) and 5(b). In the case of Mn I and Mn II, emission intensity profiles show mainly one intense peak with the maximum peak intensity varying linearly with time. Plume emission profiles 

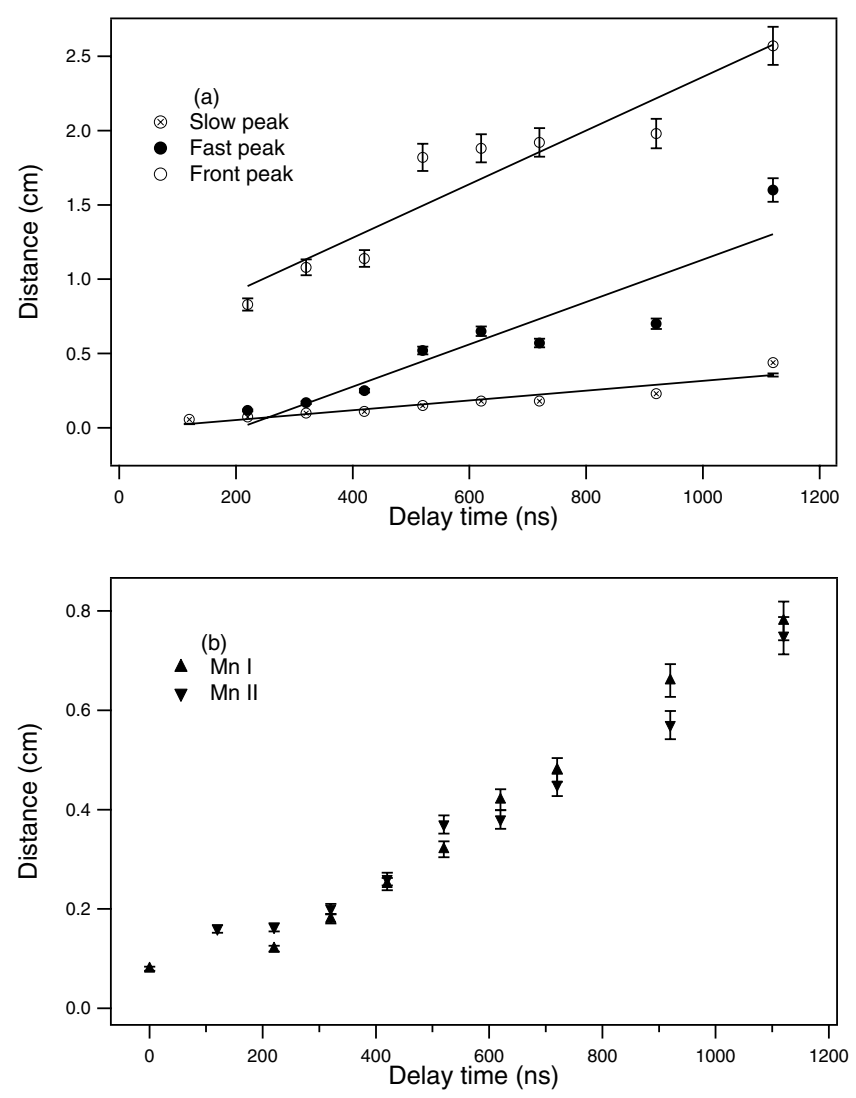

FIG. 6. Distance from the target of the maximum peak positions as a function of the delay time for (a) Li I and (b) Mn I and Mn II species.

corresponding to the $\mathrm{Li}$ I species along the expansion consist of at least three clearly distinct intensity maxima [cf. Figs. 5(a) and 5(b)]. A first maximum is observed at the leading edge of the plume, a second maximum propagates at velocities similar to those of other plume species (Mn I and Mn II), and the third maximum is observed close to the target surface. At $t \geq 920 \mathrm{~ns}$, the Li profile is elongated along the expansion direction, which can be assigned to the velocity dispersion of the three maxima. To estimate the mean velocities of the emitted components, the lateral position for the maximum intensity of the emission profiles is determined by fitting the intensity profiles using Gaussian functions. The accuracy of this procedure is limited by the quality of the fitting procedure. The as-obtained peak positions as a function of delay time for Li I, Mn I, and Mn II species are shown in Figs. 6(a) and 6(b).

Assuming a linear $d-t$ relation for the data in Fig. 6(a), the mean velocities for the three peaks of the Li I species are $2.8( \pm 0.01) \times 10^{3}, \quad 9.3( \pm 0.02) \times 10^{3}, \quad$ and $2.8( \pm 0.01)$ $\times 10^{3} \mathrm{~m} / \mathrm{s}$, respectively. The velocities of the $\mathrm{Mn}$ II and $\mathrm{Mn}$ I species [Fig. 6(b)] are $6.8( \pm 0.01) \times 10^{3}$ and $6.5( \pm 0.01)$ $\times 10^{3} \mathrm{~m} / \mathrm{s}$, respectively (see Table III). The velocities of the fastest $\mathrm{Li}$ species correspond reasonably well with the data from the spectroscopic measurements, while the velocities of the Mn species are lower compared to the values reported in Table I.

\section{Plume expansion in oxygen background gas}

The plume emission evolution at a $20 \mathrm{~Pa}$ oxygen background pressure for the Li I, Mn I, Mn II, and O I species is
TABLE III. Velocities of the ablated species as calculated from plume imaging.

\begin{tabular}{lc}
\hline \hline Species & $\begin{array}{c}\text { Velocities in vacuum } \\
(\mathrm{m} / \mathrm{s})\end{array}$ \\
\hline & $2.9( \pm 0.01) \times 10^{3}$ \\
& $9.3( \pm 0.01) \times 10^{3}$ \\
Li I & $2.8( \pm 0.01) \times 10^{4}$ \\
Mn I & $6.5 \times 10^{3}$ \\
Mn II & $6.8(0.01) \times 10^{3}$ \\
\hline \hline
\end{tabular}

shown in Fig. 7. During expansion, the plume undergoes multiple scattering with the gas species, resulting in a sharpening of the plume front. The plume is progressively decelerated, which is revealed by the increase in the emission intensity at the plume front (see Fig. 7 and compare with Fig. 4).

Interaction of the plasma plume with the background gas leads to a separation of the plume into two main components. This plume separation will be discussed in more details in Sec. IV. The effect is clearly observed for Mn I and Li I at around $420 \mathrm{~ns}$, while for Mn II the plume separation occurs earlier, i.e., 220 ns (see line in Fig. 7).

The internal plume structure is affected by the interactions between the background gas molecules and the expanding plume. ${ }^{13}$ The plume imaging data were used to analyze the evolution of the emission intensities along the expansion direction. The variation in the intensity profiles as a function of the delay time for (a) Li I, (b) Mn I, (c) Mn II, and (d) O I is shown in Fig. 8. The time scale ranges from 120 to 2120 ns. The intensities are normalized to allow a direct comparison between the different species.

The emission profiles along the expansion direction indicate that the plume front emission broadens with time. At $120 \mathrm{~ns}$ (not shown here) the emission profiles of the Mn and
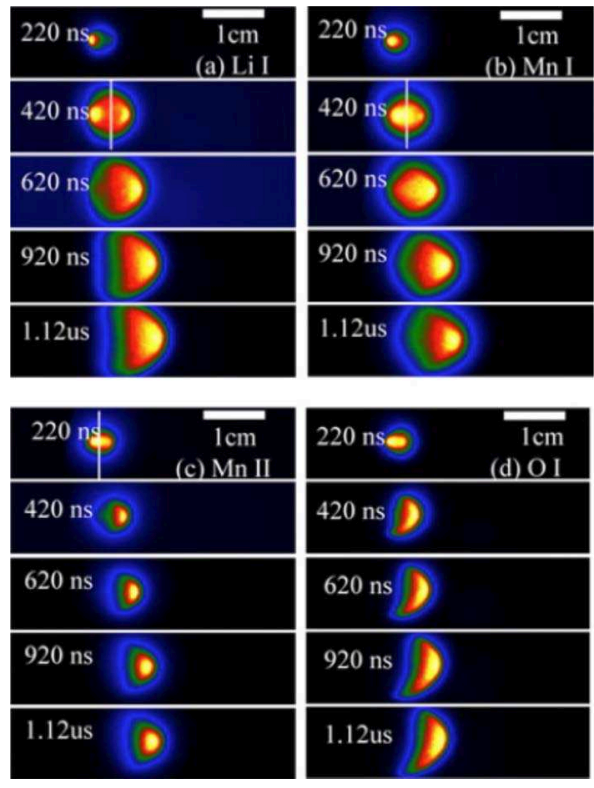

FIG. 7. (Color online) Plume emission images of the plume induced by $\mathrm{LiMn}_{2} \mathrm{O}_{4}$ ablation at a background pressure of $20 \mathrm{~Pa}$ oxygen. The time scale varies from $120 \mathrm{~ns}$ to $1.12 \mu \mathrm{s}$. All images are normalized with respect to the maximum intensity. The laser fluence was $2 \mathrm{~J} \mathrm{~cm}^{-2}$. 

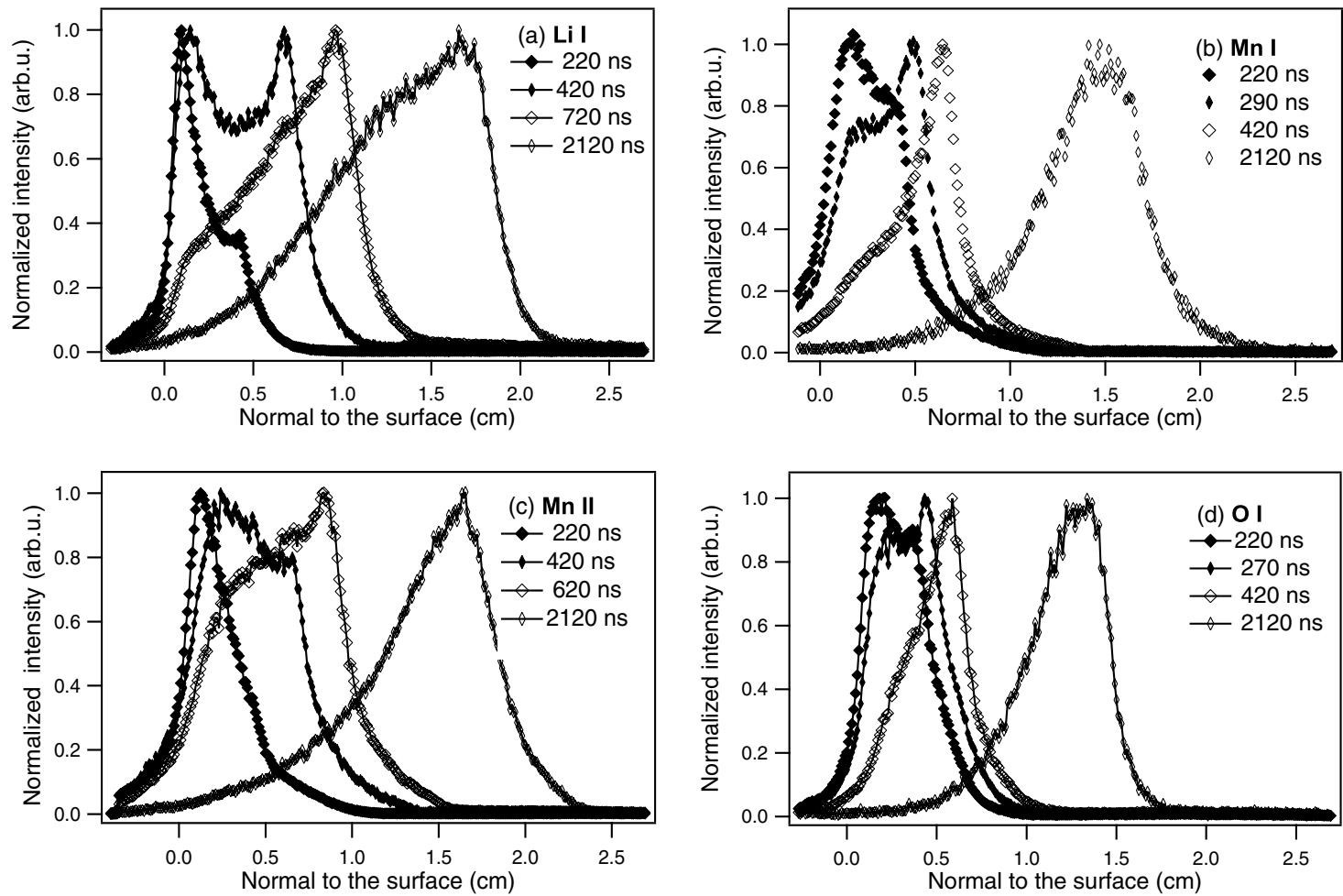

FIG. 8. Normalized emission intensity distributions perpendicular to the target for (a) Mn I, (b) Mn II, (c) Li I, and (d) O with time scale from 220 to 2210 ns and a background pressure of $20 \mathrm{~Pa}$ oxygen. The profiles were selected to show the most dominant effects that occur at different delay times for Li as compared to $\mathrm{Mn}$ and $\mathrm{O}$.

O species show a single maximum while Li already exhibits a double peak structure. The smaller peak of the emerging double peak structure of Li I after $220 \mathrm{~ns}$ is indicative of an almost collision-free expansion of the plume in agreement with the deduced expansion velocities of the species (Table I). This is also consistent with the so-called plume splitting. ${ }^{24}$

After $420 \mathrm{~ns}$, a double peak structure can be clearly observed for all species. It is most pronounced for Li I [see Fig. 8(a)] where the profile consists of a first peak close to the target surface $(0.15 \mathrm{~mm})$ and a second peak at the plume front $(0.6 \mathrm{~mm})$. The peak appearing at the plume front gains intensity in time with respect to the peak close to the target surface, while at later times, the two peaks merge. In addition, the velocity of the species slows down and becomes comparable at the later observation time.

To further study the changes in the internal plume structure, we analyzed the dependence of the position of the first $\left(z_{1}\right)$ and second peak $\left(z_{2}\right)$ positions for Li I as a function of the delay time [Fig. 9(a)], ${ }^{25}$ as well as the spatial separation of the peaks as a function of delay time [Fig. 9(b)]. The second distribution $\left(z_{2}\right)$ represents the emission arising from plasma-gas interaction while the first distribution $\left(z_{1}\right)$ is related to changes in the internal structure of the plume. Analyzing the plots in Fig. 9, three different expansion regimes are noted and indicated in the graphs. At $t<320 \mathrm{~ns}$, the plume expansion is almost collision-free, whereas a linear increase in time of the spatial separation is observed. In the interval of $320<t<720 \mathrm{~ns}$, a sudden increase in the spatial separation takes place, indicative for a backward motion of $z_{1}$ toward the target surface [see Fig. 9(b)]. After $720 \mathrm{~ns}$, the spatial separation is reduced and the distributions tend to merge at later times.
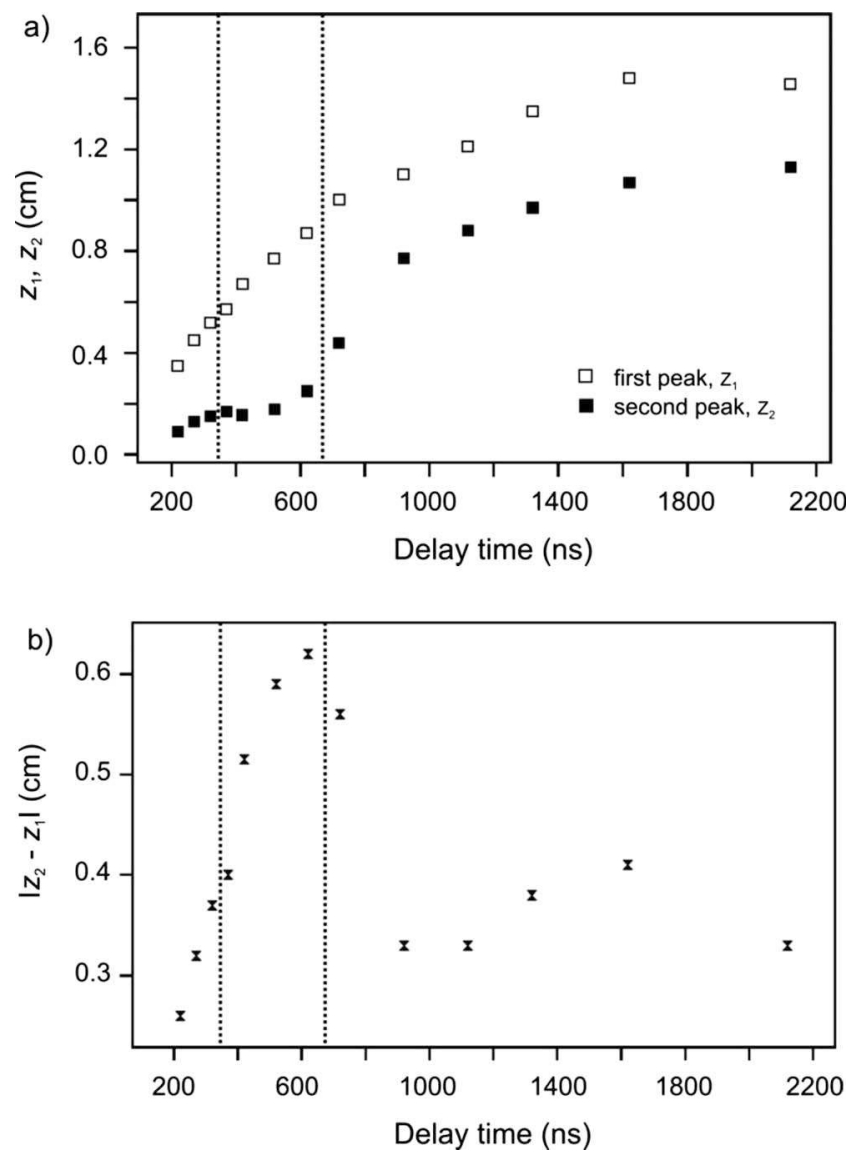

FIG. 9. (a) The dependence of the first $\left(z_{1}\right)$ and second peak $\left(z_{2}\right)$ positions as a function of the delay time and (b) the variation in the spatial separation of the peaks with time. 
The images in Fig. 7 strongly suggest a larger spatial distribution of $\mathrm{Li}$ I if compared to other plume species. To estimate the broadening of the plume front as a result of the interaction with the gas species, we evaluated the maximum transversal dimension of the plume emission as a function of the delay time. The largest expansion is found for Li I, followed by $\mathrm{Mn}$ I and Mn II. A linear increase in $R(t)$ is observed for all plume species up to $720 \mathrm{~ns}$ reaching $\sim 10 \mathrm{~mm}$ in diameter for $\mathrm{Li}$ and 7-8 $\mathrm{mm}$ for $\mathrm{Mn} \mathrm{I}$ and $\mathrm{Mn}$ II. This radial plume expansion at $720 \mathrm{~ns}$ corresponds to an expansion velocity of $\sim 1.4 \times 10^{4} \mathrm{~m} / \mathrm{s}$ for $\mathrm{Li}$ I and $\sim 1.0$ $\times 10^{4} \mathrm{~m} / \mathrm{s}$ for the Mn species. For $t>720 \mathrm{~ns}$, the plume expansion reaches a plateau, which suggests that a diffusionlike process takes place. The data show that the angular expansion of $\mathrm{Li}$ in a background gas is the largest and excited $\mathrm{Li}$ species can be observed over a large distance. An estimate for the broadening along the longitudinal expansion axis of the plume was not done because the uncertainty of the exact target position with respect to the plume front was too large to obtain meaningful data. However, the tendency for the different species moving along the longitudinal direction was broadly similar ( $\mathrm{Li}$ is spread out more than $\mathrm{Mn}$ ) compared to the data for the radial direction.

\section{DISCUSSION}

Excited $\mathrm{Li}$ ions ( $\mathrm{Li}$ II) could not be detected in the optical emission spectrum, as Li II has a low intensity within the analyzed range from 300-900 $\mathrm{nm}$. The laser-plume interaction depends strongly on the pulse duration. Here, the $35 \mathrm{~ns}$ pulse length of the $\mathrm{KrF}$ laser is already sufficiently long to ensure considerable interaction between the laser and the plume. The laser photons with a photon energy of $5 \mathrm{eV}$ should therefore provide almost enough energy to ionize excited Li species (ionization energy of $5.4 \mathrm{eV}$ ), while the ionization of $\mathrm{Mn}$ atoms (ionization energy of $7.4 \mathrm{eV}$ ) takes place through the absorption of two photons. While optical emission spectroscopy only detects neutral $\mathrm{Li}$ atoms, mass spectrometry analysis has shown that $\mathrm{Li}$ ions are the main species in the plume. ${ }^{8}$

\section{A. Plume expansion in vacuum}

The emission spectroscopy data indicate that the Mn II species exhibit a higher velocity than Mn I. The observation that ions are faster than neutrals agrees with the previous reports, e.g., Ref. 26. This can be explained by the creation of a double layer in the plume in which ions are accelerated between electron-rich and electron-depleted regions.

Plasma parameters such as electron density $\left(N_{e}\right)$, electron temperature $\left(T_{e}\right)$, and plume velocity can be extracted from plume emission spectra. One approach is to assume that the plasma plume is in the local thermodynamical equilibrium (LTE). In this case, $T_{e}$ and $N_{e}$ can be determined based on a simple model. ${ }^{27}$ Another approach to extract $T_{e}$ and $N_{e}$ is the analysis for time-of-flight measurements as proposed by Lunney and co-workers, ${ }^{16,17}$ which has not been done for the data presented. ${ }^{28}$

The electron density can be extracted from the emission line broadening of the laser plasma spectrum, the broadening
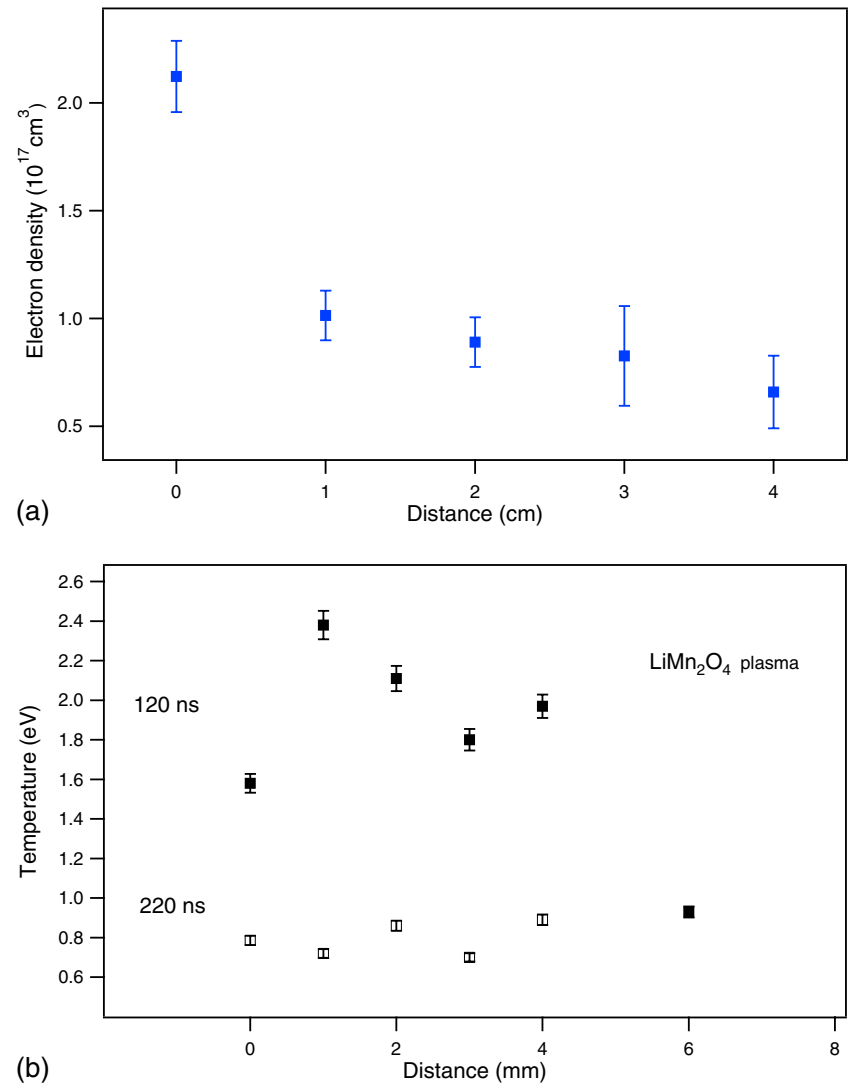

FIG. 10. (Color online) (a) Spatial distribution of the electron density at 120 ns obtained from the Stark broadening of the $670 \mathrm{~nm}$ lithium transition. (b) Spatial distribution of the electron temperature at a delay time of 120 and $220 \mathrm{~ns}$.

being a contribution of the Doppler and Stark effect. Here the Doppler broadening induced by the Doppler shifts $(\Delta \lambda$ $\left.=\lambda v_{z} / c\right)$ in different species expanding with different velocities $\left(v_{z}\right)$ is negligible. For instance the $\mathrm{Li}$ I species expanding with $v_{z} \approx 1.8 \times 10^{4} \mathrm{~m} / \mathrm{s}$ contributes to a Doppler broadening of $\approx 0.4 \AA$. Stark broadening predominantly caused by electron-atom collisions is given by the expression $2 W^{*}\left(N_{e} / 10^{16}\right)$, where $W$ is the electron impact factor. The electron density as a function of the distance from the target surface [see Fig. 10(a)] was calculated using the Li I line at $670.7 \mathrm{~nm}$, corresponding to a $1 s^{2} 2 p \rightarrow 1 s^{2} 2 s$ transition.

The electron temperature in the plasma can be determined from the relative line intensity ratio of two isolated lines $\lambda_{\mathrm{mn}}^{1}$ and $\lambda_{\mathrm{mn}}^{2}$ emitted from the same atomic or ionic species $I_{1} / I_{2}=\left(g_{m}^{1} A_{m n}^{1} \lambda_{m n}^{2} / g_{m}^{2} A_{m n}^{2} \lambda_{m n}^{1}\right) \exp \left[\left(E_{2}-E_{1}\right) / k T_{e}\right]$, where $A_{m n}$ is the transition probability from the energy levels $m$ to $n, g_{m}$ is the statistical weight of the upper energy level, and $E_{m}$ is the energy of the upper energy state $m$. The electron temperature was calculated from the Mn II lines at 346 and $347 \mathrm{~nm}$ using known values for $A_{m n}$ and $g_{m}{ }^{29}$ The dependence of the electron temperature on the distance at 120 and $220 \mathrm{~ns}$ is shown in Fig. 10(b). At a delay time of $120 \mathrm{ns,}$ the electron temperature varies between 2.4 and $0.8 \mathrm{eV}$. After $120 \mathrm{~ns}$ the electron temperature remains roughly constant at $\sim 0.8 \mathrm{eV}$. Our observations are in agreement with the previously reported data. ${ }^{30}$

The calculations for $N_{e}$ and $T_{s}$ were carried out under the assumption that the plasma is in a LTE. A necessary criterion 
for this assumption is $N_{e} \geq 1.4 \times 10^{14} T_{e}^{1 / 2}\left(\Delta E_{m n}\right)^{3} \mathrm{~cm}^{-3},{ }^{31}$ where $\Delta E_{m n}(\mathrm{eV})$ is the difference between the upper and lower energy levels. For Li I, $\Delta E_{m n}=1.84 \mathrm{eV},{ }^{29}$ the electron density is $N_{e} \sim 1 \times 10^{15} \mathrm{~cm}^{-3}$. This value of $N_{e}$ shows that the assumption made to extract $N_{e}$ and $T_{s}$ is justified.

The velocities of plasma species were likewise extracted from optical emission spectra. In the presence of the background gas, these velocities are reduced due to collisions with the gas molecules. This is shown in Table I, where the velocities of the excited species in both vacuum and gas were calculated using linear fits.

The emission spectroscopy data have shown the presence of the Li I species up to $820 \mathrm{~ns}$, i.e., twice the time scale compared with Mn I and Mn II species. In order to discuss the temporal evolution of the emission, the lifetime of the excited species (time of the 1/ $e$ decay of the intensity) needs to be considered. This lifetime for $\mathrm{Li} \mathrm{I}$ is $\sim 3$ times longer than Mn II (see Table I) and $\sim 5$ times longer than Mn I. It is worth mentioning that in optical emission spectroscopy, not only excited species created during the ablation process are detected, but also species formed and excited during plume expansion. The observation of plume species over a few hundred nanoseconds indicates that excitation processes occur during the plume expansion. A likely mechanism is the recombination and re-excitations of plume species due to collisions with electrons and other plume species, which allows for a prolonged detection.

The temporal evolution of the emission intensity arising from $\mathrm{Li}$ species up to $820 \mathrm{~ns}$ suggests complex excitation processes to occur, even more complex and pronounced than observed for Mn. The behavior of the Li species and their dynamics in the plasma plume have been studied before. ${ }^{32}$ Laser induced fluorescence (LIF) studies on $\mathrm{LiNbO}_{3}$ ablation in vacuum have shown that $\mathrm{Li}$ exhibits two distinct distributions: a direct plume expansion and a delayed Li I ejection. ${ }^{32}$ The delayed release of $\mathrm{Li}$ occurs after several microseconds.

The images shown in Fig. 4 for the vacuum deposition of $\mathrm{LiMn}_{2} \mathrm{O}_{4}$ cover a shorter time scale than reported in Ref. 32 . We find that the plume corresponding to the lithium species is more elongated along the normal to the target, while the plume corresponding to the Mn species has a spherical shape. This is clearly observed at a delay time of $1.12 \mu \mathrm{s}$, where the emission intensity of the Li I species expands over the $3 \mathrm{~cm}$ spatial resolution. The plume elongation corresponding to the $\mathrm{Li}$ species can be largely accounted for by the high velocities of the $\mathrm{Li}$ species in the plume.

The variation in the emission intensities as a function of the delay time (Fig. 4) reveals that after a few hundred nanoseconds, the plume emission corresponding to Li I develops at least three clearly distinct peaks or peaklike structures. The fastest peak at the plume front travels with an average velocity of around $2.8 \times 10^{4} \mathrm{~m} / \mathrm{s}$, the second plume distribution peak travels with a comparable velocity to $\mathrm{Mn}$ I and Mn II, while the third peak (next to the target surface) moves at a velocity of $2.9 \times 10^{3} \mathrm{~m} / \mathrm{s}$ (see Table III).

The presence of a fast component in the plume induced by the ablation of a $\mathrm{LiMn}_{2} \mathrm{O}_{4}$ target indicates that mainly $\mathrm{Li}$ species are found at the plume front, while the rest of the plume consists of a mixture of light and heavy atoms $(\mathrm{O}, \mathrm{Li}$, and $\mathrm{Mn}$ ). In order to explain the origin of the fast component, we argue that the plume species desorb from the surface with a Maxwell-Boltzmann velocity distribution ${ }^{33}$ with a temperature $T_{0}$ and a mean thermal velocity $\nu_{i}$ given by

$$
v_{i}=\left(8 k_{B} T_{0} / \pi m_{i}\right)^{1 / 2},
$$

where $k_{B}$ is the Boltzmann constant and $m_{i}$ is the corresponding mass species. The studied material $\mathrm{LiMn}_{2} \mathrm{O}_{4}$ contains three species with a mass ratio $\mathrm{Li}: \mathrm{O}: \mathrm{Mn}$ of 7: 16: 55 . Assuming that all species have the same temperature $T_{0}$ under laser irradiation, the velocities of the species scale as $v_{\mathrm{Li}}: v_{\mathrm{O}}: v_{\mathrm{Mn}} \sim a^{*}(0.38: 0.25: 0.13)$, where $a$ is a proportionality constant. The Li species will therefore show the highest velocities. This simple approximation is in agreement with our observation that at early times the plume front consists mainly of light particles.

During plume expansion, multiple scattering between plume species may occur. The collision between $\mathrm{Li}$ and $\mathrm{Mn}$ species results in a slight deceleration of $\mathrm{Li}$ to a velocity comparable with $\mathrm{Mn}$. As a result, a second plume component is formed. The third plume component exhibits a well defined interface and large contact area with the surface of the target [visible at a delay time of $620 \mathrm{~ns}$, see Fig. 4(a)]. As Li is the lightest plume component with a high scattering probability, this gives rise to a wide angular $\mathrm{Li}$ expansion.

To account for the large Li deficiency in $\mathrm{LiMn}_{2} \mathrm{O}_{4}$ thin films prepared under vacuum conditions, our measurements identify at least three sources. The high velocity of the $\mathrm{Li}$ species and their large kinetic energy result in a preferential resputtering of $\mathrm{Li}$ for an already deposited film. In addition, the sticking coefficient of $\mathrm{Li}$ on a substrate is probably small. The combination of a large kinetic energy and a small sticking coefficient for a species reduces the probability of a correct $\mathrm{Li}$ content in the film. Further, the wide angular expansion for $\mathrm{Li}$ as compared to $\mathrm{Mn}$ in the plume changes the $\mathrm{Li} / \mathrm{Mn}$ ratio per solid angle element, such that the required $\mathrm{Li} / \mathrm{Mn}$ ratio to grow $\mathrm{LiMn}_{2} \mathrm{O}_{4}$ from a stoichiometric target cannot be met.

\section{B. Plume expansion in $20 \mathrm{~Pa} \mathrm{O}_{2}$ background}

A detailed analysis of the plume dynamics in an oxygen background atmosphere is of significant interest because the Li content in $\mathrm{LiMn}_{2} \mathrm{O}_{4}$ thin films increases with pressure, reaching a maximum around $20 \mathrm{~Pa}$; however, these films are still Li deficient. ${ }^{4}$ Experimentally, a larger angular distribution of all the species in the plume is observed. This results in thinner films due to a lower growth rate as compared to films deposited at a lower pressure. The angular differences of $\mathrm{Li}$ in the spatial distribution versus $\mathrm{Mn}$ at this pressure are expected to be observable in the average film composition, i.e., a $\mathrm{Li} / \mathrm{Mn}$ ratio different from the target.

In a background gas, the mean free path of the plume species is considerably reduced due to collisions with background molecules. The mean free path of atoms (with a velocity much higher than the mean thermal velocity) in a gas with another species is given by 
TABLE IV. Mean free path and scattering cross section of the Li, Mn, and $\mathrm{O}$ species in $20 \mathrm{~Pa} \mathrm{O}_{2}$. The atomic mass, atomic radius, and scattering cross sections are included.

\begin{tabular}{lccc}
\hline \hline Species & $\begin{array}{c}\text { Mass } \\
(\mathrm{amu})\end{array}$ & $\begin{array}{c}\text { Radius } \\
(\AA)\end{array}$ & $\begin{array}{c}\lambda_{1} \\
(\mathrm{~mm})\end{array}$ \\
\hline $\mathrm{Li}$ & 6.94 & 2.05 & 1.8 \\
$\mathrm{Mn}$ & 55 & 1.79 & 2 \\
$\mathrm{O}$ & 16 & 0.65 & 4.4 \\
$\mathrm{O}_{2}$ & 32 & 1.8 & $\cdots$ \\
\hline \hline
\end{tabular}

$$
\lambda_{1}=\left(k_{B} T\right) /\left(\pi P d_{12}^{2}\right),
$$

where $T$ is the temperature of the gas and $d_{12}=\left(d_{1}+d_{2}\right) / 2$ is the impact factor $\left(d_{1}\right.$ and $d_{2}$ are the diameters of the species 1 and 2). The calculated mean free paths of $\mathrm{Li}, \mathrm{Mn}$, and $\mathrm{O}$ species in $20 \mathrm{~Pa}$ oxygen are summarized in Table IV together with the corresponding atomic masses. The data show that all species have a mean free path of the order of a few millimeters. The ratio $\lambda(\mathrm{Mn}) / \lambda(\mathrm{Li}) \sim 1.1$ indicates that $\mathrm{Li}$ and $\mathrm{Mn}$ species have a comparable collision probability during expansion in the oxygen background gas. The mass ratio $m(\mathrm{Mn}) / m(\mathrm{Li}) \sim 8$ suggests that a wide angular distribution of $\mathrm{Li}$ compared to the $\mathrm{Mn}$ species is possible and this is in agreement with our experimental observations. The mean free path of $\mathrm{O}$ is the highest of all plume species, $\lambda(\mathrm{O}) / \lambda(\mathrm{Li}) \sim 2.4$. The calculated mean free paths are much lower than the observed expansion distances of the "fast peak," suggesting that these species likewise have undergone some collisions as confirmed by the reduced velocities deduced from Fig. 3. The mean free path of the particles is reduced from a few centimeters in vacuum to a few millimeters in the presence of a background gas. Theoretical simulations have shown that under conditions when the mean free path of the species is approaching the plume dimensions, a compression of both plasma and gas occurs resulting in shock wave formation. ${ }^{24}$

The scattering cross sections of the species were determined assuming that the first peak of the plume suffers almost no collisions with the background gas molecules. Thus the integrated signal at a given distance can be defined as

$$
N_{g}=N_{0} \exp \left(-n_{g} \sigma d\right)
$$

where $n_{g}\left(\mathrm{~cm}^{-3}\right)$ is the gas density, $\sigma\left(\mathrm{cm}^{2}\right)$ is the collisional cross section, and $d$ is the observation distance. ${ }^{34}$ The scattering cross sections of $\mathrm{Li}, \mathrm{Mn}$, and $\mathrm{O}$ species with gas molecules are $4.7( \pm 0.4) \times 10^{-15}, \quad 3.6( \pm 0.5) \times 10^{-15}$, and $1.85( \pm 0.4) \times 10^{-15} \mathrm{~cm}^{2}$, respectively. The ratio $\sigma_{\mathrm{Li}} / \sigma_{\mathrm{O}}$ $\sim 2.5$ corresponds well with the calculated mean free path. These values should be compared with $2.3 \times 10^{-16} \mathrm{~cm}^{2}$ obtained for $\mathrm{YBa}_{2} \mathrm{Cu}_{3} \mathrm{O}_{7-x}$ at $40 \mathrm{~Pa} \mathrm{O}_{2}$. ${ }^{24}$

The plume length $L_{p}$ estimated using the adiabatic expansion can be described by ${ }^{30}$

$$
L_{p}=A[(\gamma-1) E]^{1 /(3 \gamma)} P^{-1 /(3 \gamma)} V^{(\gamma-1) /(\gamma-3)},
$$

where $A$ is a geometrical factor that depends on the expansion geometry, $\gamma$ is the specific heat ratio of the vapor, $E$ is the laser energy per pulse, $P$ is the ambient gas pressure, and $V=v_{0} \times \tau \times$ spot size $\left(\tau\right.$ is the pulse duration, $v_{0}$ is initial velocity). With $\gamma=1.4,{ }^{31} P=10^{-4} \mathrm{~Pa}$, vacuum velocity $v_{0}$ $=\left(0.65-1.8 \times 10^{4} \mathrm{~m} / \mathrm{s}\right), \tau=34 \mathrm{~ns}$, a spot size of $1 \mathrm{~mm}^{2}$, and $A=1.5$, the plume length obtained is $L_{p}$ $=33.3( \pm 5) \mathrm{mm}$. If we consider a typically used target-tosubstrate distance of $40 \mathrm{~mm}$, we conclude that the film growth occurs in the region between plume expansion and the diffusion regime. Hence, species in the plume suffer from multiple scattering before reaching a substrate and a targetsubstrate distance of $40 \mathrm{~mm}$ corresponds to $\sim 22 \lambda$ for $\mathrm{Li}$ and $10 \lambda$ for $\mathrm{O}$.

The time resolved ICCD imaging technique allows to study the temporal evolution of an expanding plume, thereby monitoring simultaneously the separation of the species in the plume and the changes in the internal plume structure as a result of the species interaction with a background gaslike oxygen. Spatially resolved emission profiles along the normal to the target surface (Fig. 8) show that the emission profile broadens with time if $\mathrm{LiMn}_{2} \mathrm{O}_{4}$ is ablated in an oxygen background pressure of $20 \mathrm{~Pa}^{35}$ At $t<120 \mathrm{~ns}$, the emission profile consists of a single distribution that progressively moves away from the surface. After a few hundred nanoseconds, a distinct separation of the plume is observed for all species. The maximum at the front of the plume $z_{2}$ represents the emission arising from the plasma-gas interaction, while the distribution close to the target surface $z_{1}$ is related to changes in the internal plume structure (Fig. 8). At the later times, the two distributions tend to merge in a single peak distribution, where the maximum intensity moves progressively with time toward the front edge of the plume. This suggests a deceleration of the species in the front part of the plume while still expanding in a background gas. ${ }^{36}$ The dynamics of the plume peak distributions are shown in Fig. 9 for the Li species. The dependence of the plume front peak $z_{2}$ as a function of the delay time indicates an attenuation effect due to collisions with the surrounding gas. It has also the characteristic hall marks of a shockwave with a $t^{2 / 5}$ dependence. ${ }^{15}$ The peak close to the target surface $z_{1}$ moves slowly away from the surface, whereas the separation between the two peaks increases linearly with time. Between 320 and $620 \mathrm{~ns}$ the $z_{1}$ peak is pushed back toward the target surface. Later, the peak separation decreases again. The appearance of the peak close to the target surface may be due to creation of a shockwave that moves inward the plume. Interactions of the particles scattered backward the target surface with the incoming plume species may explain the appearance of the distribution close to the target surface.

The expansion of a laser-produced plasma within a background pressure is a far more complex phenomenon than the expansion into vacuum due to the plume-background gas interaction. Aspects such as plume deceleration, shock wave formation, thermalization, and "plume splitting" have been observed. ${ }^{37-40}$ The latter point is associated with the detection of fast and slow species in the plasma plume. One species is expanding collision-free with the same velocity like in vacuum. Other species are slowed down by collisions with the background gas. At first sight this seems to be similar to our observations, but it is necessary to consider that the classical plume splitting is mainly detected by ion probe, mass spectrometry, and absorption measurements where nonex- 
cited species are detected. ${ }^{41-44}$ There are also some data for emission spectroscopy ${ }^{45}$ but with very low intensities for the fast moving species. The low intensity in emission studies results from the short lifetime of the excited state species and the absence of collisional re-excitation (the species travel collision-free). In our experiments, the fast species have a very high intensity detected on a time scale much longer than the lifetime of the excited state species. The very high intensities observed over a long time scale in combination with the largely different expansion velocities are not consistent with the conventional plume splitting also observed for $t$ $<420$ ns. We therefore conclude that other additional mechanisms must be present to account for the observations at longer time scales.

One possible mechanism is the above mentioned delayed ejection of $\mathrm{Li}$ as observed for lithium niobate, ${ }^{32}$ but the $\mathrm{Li}$ release has been recorded at 2-20 $\mu$ s after the laser pulse and was measured by laser-induced fluorescence, a technique probing nonradiative species. In our experiments, the second species (not only Li) are detected a few hundred nanoseconds after the pulse as excited species. Therefore, a delayed emission model cannot explain our data. Emission measurements were done on the ablation of LiF (Ref. 46) reported for the Li intensity versus distance profiles, a two-peak structure on the time scale of 600-800 ns, and a time scale similar to our measurements. The two-peak structure was assigned to the self-absorption of the Li ground states. Contrary to the presented measurements, the measurements by Henley et $a l^{46}$ were conducted in vacuum and the two-peak structure was reported for Li only, whereas the two-peak structure reported here is observed in the presence of a background gas and for all plasma plume species. We therefore consider another mechanism as the most prominent source for the two-peak structure in our measurements, namely, a backward scattering of plume species from the collision with the background gas molecules. These backward scattered molecules interact with the slower plume species, resulting in the appearance of the second slower peak (Fig. 8). This backscattering mechanism has been reported for similar time scales, oxygen background pressure, and intensity ratios in the case of $\mathrm{LaMnO}_{3}$ by Amoruso at al. ${ }^{25}$ Here, the authors are using plume imaging without the benefit of a spectral resolution. We therefore consider that the backward scattering mechanism, as suggested in Ref. 25, is the origin of the two-peak structure in our measurements. Our data support this mechanism strongly as the most pronounced two-peak structure is observed for the lightest element $\mathrm{Li}$, which can be backward scattered most easily among the plume species.

The backscattering effect of the Li I species in the plume is also strongly related with the plume broadening. The plume broadening, as characterized by the parameter $R$, increases linearly with time until $720 \mathrm{~ns}$, while at a later time a plateau is reached. This suggests that the plume diffuses slowly in background gas until the plume stopping effects set in. The largest scattering probability of the light species ( $\mathrm{Li}$ I) is reflected in the largest broadening of the plume observed for the Li I species due to the shock wave moving inward. As a consequence, the neutral $\mathrm{Li}$ species generated during the ablation process are distributed over a larger angular volume with a considerable angular broadening, while the Mn atoms are more confined to a forward direction. The significant scattering of the light particles in the plume with the gas molecules induces a significant plume broadening, which can explain the observed Li deficiency in the as-grown film. Overall the data suggest that a congruent transfer of a light element such as $\mathrm{Li}$ is difficult to realize in the presence of heavier elements, and these light element deficiencies can only be overcome by using targets with an excess of the light element.

\section{CONCLUSIONS}

Time resolved emission spectroscopy measurements have been performed on the laser induced plasma plume of a $\mathrm{LiMn}_{2} \mathrm{O}_{4}$ target in vacuum and at an oxygen background pressure of $20 \mathrm{~Pa}$. The fast expansion of $\mathrm{Li}$ species in vacuum when compared to Mn species leads to an elongation of the plume emission along the expansion direction after a few hundred nanoseconds, while the emission of Mn species remains spherical. It was found that $\mathrm{Li}$ as the lightest plume component gives rise to a wide angular $\mathrm{Li}$ expansion as compared with $\mathrm{Mn}$. Hence the $\mathrm{Li} / \mathrm{Mn}$ ratio for the ablation of $\mathrm{LiMn}_{2} \mathrm{O}_{4}$ in vacuum will always be such that a congruent transfer of $\mathrm{Li}$ and $\mathrm{Mn}$ from a stoichiometric target is not possible.

For the ablation of $\mathrm{LiMn}_{2} \mathrm{O}_{4}$ in an oxygen background pressure, plume species are slowed down due to collisions with the background gas molecules. A plume-separation effect is observed during the plume propagation in the background gas. The effect originates from the collisions of the plume front with the background gas, which results in a deceleration of the plume front and backward scattering of the particles. The interaction of the backscattered particles with the incoming particles gives rise to a secondary peak close to the target surface and a broadening of the plume. Like for the vacuum expansion of the plume, the angular distribution of $\mathrm{Li}$ species in a background gas is wider as compared to $\mathrm{Mn}$, and the $\mathrm{Li} / \mathrm{Mn}$ ratio reaching a substrate will always be such that thin films of $\mathrm{LiMn}_{2} \mathrm{O}_{4}$ prepared from stoichiometric targets will be Li deficient. The implication from these experiments is that laser ablation of materials containing a combination of light and heavy elements will always lead to a deficiency of the light element in the as-grown film. If the mass ratio between the light and the heavy element is not too different, is should be possible to find a set of deposition parameters that will result in the growth of a film with the envisaged composition.

${ }^{1}$ Y. Konishi, M. Izumi, T. Manako, M. Kasai, H. Kuwahara, M. Kawasaki, K. Terakura, and Y. Tokura, J. Phys. Soc. Jpn. 68, 3790 (1999).

${ }^{2}$ M. Allegrini, F. Fuso, G. Lorenzi, L. N. Vyacheslavov, and E. Arimondo, Appl. Surf. Sci. 106, 438 (1996).

${ }^{3}$ C. Julien, E. Haro-Poniatowski, M. A. Camacho-Lopez, L. EscobarAlarcon, and J. Jimenez-Jarquin, Mater. Sci. Eng., B 72, 36 (2000).

${ }^{4}$ T. Dumont, T. Lippert, M. Dobeli, H. Grimmer, J. Ufheil, P. Novak, A. Wursig, U. Vogt, and A. Wokaun, Appl. Surf. Sci. 252, 4902 (2006).

${ }^{5}$ K. A. Striebel, C. Z. Deng, S. J. Wen, and E. J. Cairns, J. Electrochem. Soc. 143, 1821 (1996).

${ }^{6}$ C. Julien, M. A. Camacho-Lopez, L. Escobar-Alarcon, and E. HaroPoniatowski, Mater. Chem. Phys. 68, 210 (2001).

${ }^{7}$ A. Perea, J. Gonzalo, C. N. Afonso, C. Vivien, and L. Ch, Appl. Phys. A: 
Mater. Sci. Process. 69, S141 (1999).

${ }^{8}$ D. O' Mahony, J. Lunney, Th. Dumont, S. Canulescu, T. Lippert, and A. Wokaun, Appl. Surf. Sci. 254, 811 (2007).

${ }^{9}$ S. Amoruso, J. Schou, and J. G. Lunney, Europhys. Lett. 76, 436 (2006).

${ }^{10}$ J. Giapintzakis, A. Sfounis, and M. Velegrakis, Int. J. Mass. Spectrom. 189, 1 (1999).

${ }^{11}$ H. Dang, M. Zhou, and Q. Qin, Appl. Surf. Sci. 140, 118 (1999).

${ }^{12}$ C. J. Druffner, G. P. Perram, and R. R. Biggers, Rev. Sci. Instrum. 76 093101 (2005).

${ }^{13}$ S. Amoruso, A. Sambri, M. Vitiello, and X. Wang, Appl. Surf. Sci. 252, 4712 (2006).

${ }^{14}$ N. Arnold, J. Gruber, and J. Heitz, Appl. Phys. A: Mater. Sci. Process. 69, S87 (1999).

${ }^{15}$ S. Amoruso, R. Bruzzese, N. Spinelli, and R. Velotta, J. Phys. B 32, R131 (1999).

${ }^{16}$ J. G. Lunney, B. Doggett, and Y. Kaufmann, J. Phys.: Conf. Ser. 59, 470 (2007).

${ }^{17}$ J. G. Lunney and B. Doggett, Proc. SPIE 6261, 62610B (2006).

${ }^{18}$ S. I. Anisimov, B. S. Luk'yanchuk, and A. Luches, Appl. Surf. Sci. 96-98, 24 (1996).

${ }^{19}$ R. K. Singh and J. Narayan, Phys. Rev. B 41, 8843 (1990).

${ }^{20}$ P. Lecoeur, A. Gupta, P. R. Duncombe, G. Q. Gong, and G. Xiao, J. Appl. Phys. 80, 513 (1996)

${ }^{21}$ S. Amoruso, R. Bruzzese, R. Velotta, N. Spinelli, M. Vitiello, and X. Wang, Appl. Surf. Sci. 248, 45 (2005).

${ }^{22}$ S. I. Anisimov, D. Bäuerle, and B. S. Luk'yanchuk, Phys. Rev. B 48, 12076 (1993).

${ }^{23}$ K. R. Chen, J. N. LeBoeuf, R. F. Wood, D. B. Geohegan, J. M. Donato, C. L. Liu, and A. A. Puretzky, Phys. Rev. Lett. 75, 4706 (1995).

${ }^{24}$ D. B. Geohegan and A. A. Puretzky, Appl. Phys. Lett. 67, 197 (1995).

${ }^{25}$ S. Amoruso, A. Sambri, and X. Wang, J. Appl. Phys. 100, 013302 (2006)

${ }^{26}$ M. Tanaka, Y. Fujisawa, T. Nakajima, Y. Tasaka, K. Ota, and S. Usami, J. Appl. Phys. 83, 3379 (1998).
${ }^{27}$ X. Hou, L. Pan, Y. Sun, Y. Li, Y. He, and H. Qi, Appl. Surf. Sci. 227, 325 (2004).

${ }^{28}$ S. Canulescu et al. (unpublished).

${ }^{29}$ NIST database, http://physics.nist.gov/PhysRefData/contents.html.

${ }^{30}$ S. S. Harilal, C. V. Bindhu, V. P. N. Nampoori, and C. P. G. Vallabhan, Appl. Spectrosc. 52, 449 (1998).

${ }^{31}$ G. Bekefi, Principles of Laser Plasmas (Wiley, New York, 1976).

${ }^{32}$ J. A. Chaos, R. W. Dreyfus, A. Perea, R. Serna, J. Gonzalo, and C. N. Afonso, Appl. Phys. Lett. 76, 649 (2000)

${ }^{33}$ J. B. Bates, N. J. Dudney, G. R. Gruzalski, R. A. Zuhr, A. Choudhury, C. F. Luck, and J. D. Robertson, J. Power Sources 43, 103 (1993).

${ }^{34}$ R. F. Wood, K. R. Chen, J. N. Leboeuf, A. A. Puretzsky, and D. B. Geohegan, Phys. Rev. Lett. 79, 1571 (1997).

${ }^{35}$ V. Berardi, S. Amoruso, N. Spinelli, M. Armenante, R. Velotta, F. Fuso, M. Allegrini, and E. Arimondo, J. Appl. Phys. 76, 8077 (1994).

${ }^{36}$ G. G. Amatucci, J. M. Tarascon, and L. C. Klein, J. Electrochem. Soc. 143, 1114 (1996)

${ }^{37}$ S. Amoruso, B. Toftmann, and J. Schou, Phys. Rev. E 69, 056403 (2004).

${ }^{38}$ S. S. Harilal, C. V. Bindhu, M. S. Tillack, F. Najmabadi, and A. C. Gaeris, J. Appl. Phys. 93, 2380 (2003).

${ }^{39}$ T. E. Itina, J. Hermann, P. Delaporte, and M. Sentis, Phys. Rev. E 66, 066406 (2002)

${ }^{40}$ R. F. Wood, K. R. Chen, J. N. Leboeuf, A. A. Puretzsky, and D. B. Geohegan, Phys. Rev. Lett. 79, 1571 (1997).

${ }^{41}$ D. B. Geohegan, in Pulsed Laser Deposition of Thin Films, edited by D. B. Chrisey and G. K. Hubler (Wiley, New York, 1994), p. 115.

${ }^{42}$ D. B. Geohegan and D. N. Mashburn, Appl. Phys. Lett. 55, 2345 (1989).

${ }^{43}$ S. Amoruso, R. Bruzzese, N. Spinelli, and R. Velotta, J. Phys. B 32, R131 (1999).

${ }^{44}$ D. B. Geohegan and A. A. Puretzky, Appl. Phys. Lett. 67, 197 (1995).

${ }^{45}$ D. B. Geohegan and A. A. Puretzky, Appl. Surf. Sci. 96-98, 131 (1996).

${ }^{46}$ S. J. Henley, G. M. Fuge, and M. N. R. Ashfold, J. Appl. Phys. 97, 023304 (2005). 